\title{
Phantom Pain, CTCAE 5.0
}

National Cancer Institute

\section{Source}

National Cancer Institute. Phantom Pain, CT CAE 5.0. NCI Thesaurus. Code C146682.

A disorder characterized by a sensation of marked discomfort related to a limb or an organ that is removed from or is not physically part of the body. 